\title{
Association of Socio-Economic Factors with the Nutritional Status of the Children Aged 2-8 Years from Slums of Kolkata, West Bengal, India
}

\author{
Enakshi Bose ${ }^{1}$, Gopal Chandra Mandal ${ }^{2, *}$ and Subha Ray ${ }^{1}$ \\ ${ }^{1}$ Department of Anthropology, University of Calcutta, Kolkata, India \\ ${ }^{2}$ Department of Anthrolpology, Bangabasi College, Kolkata, India
}

\begin{abstract}
Background: Undernutrition appears to be a plaguing factor for physical and cognitive development of a large proportion of Indian children living in impoverished conditions. The city of Kolkata, located in the eastern part of India has demonstrated a conspicuous rise in its slum growth profile in the past few decades. Hitherto, studies on physical growth and nutritional status of slum children are lacking.

Objectives: To Investigate the nutritional status (stunting, wasting, and underweight) among 2- 8 year old children and to observe the association of socio-economic factors with undernutrition of the studied children.

Materials and Methods: This cross sectional study was conducted on 185 children aged 2 to 8 years residing at slums of Tangra, Behala, and Dum Dum regions of Kolkata. Anthropometric measurements (height and weight) were take following standard protocol (Lohman et al., 1988), Socio-economic information were collected using a semi-structured questionnaire. Stunting, Underweight and Wasting were derived to evaluate the nutritional status of the studied population. Pearson correlation ( $r$ ) coefficient test was undertaken to measure the association of some socio-economic variables on undernutrition.

Results: The prevalence of stunting, underweight, and wasting were $38.91 \%$ (boys $32.14 \%$ and girls $45.45 \%$ ), $50.27 \%$ (boys $51.16 \%$, girls $49.49 \%$ ), $31.35 \%$ (boys $30.23 \%$, girls $32.32 \%$ ) respectively. The present study showed the positive correlation ( $r$ ) between educational levels of the parents and stunting, underweight and wasting independently. But household size has a negative correlation with all the three measures of nutritional status.
\end{abstract}

Conclusion: We conclude that the slum children were facing a nutritional health risk and parental education and household size appeared to be the primary reasons.

Keywords: Undernutrition, parental education, household size, slum children, Kolkata.

\section{INTRODUCTION}

Undernutrition is one of the most important global health problems affecting a large number of children in developing countries. It is estimated that elimination of undernutrition may prevent $35 \%$ of child deaths globally [1]. Poor nutrition of children do not only affects the cognitive development of children but also likely to reduce the work capacity in future. In 2006, closer to 9.7 million children died before their fifth birthday [1]. The most vulnerable members of a family are preschool children because a child without adequate nourishment is highly vulnerable to viral, bacterial and parasitic diseases [2]. Nutrition is one of the basic requirements of any living organism to grow and sustain life. However, the quality and quality of nutrients necessary for normal growth and to keep an organism in good health during its life span varies with the age of the organism. Any major deviation in the nutrient intake either in quality or in quantity from its requirement can also affect growth and life span in a

*Address correspondence to this author at the Department of Anthropology, Bangabasi College, Kolkata, India; Tel: 09433773205;

E-mail:golmal_anth@rediffmail.com number of ways, particularly in the later period / growth [3]. Infants and preschool children in developing countries form an important vulnerable segment and suffer the highest rate of mortality and morbidity [4].

In the last few decades, there has been a radical change in the socio-cultural and economic scenario of India. Large scale migration to cities for a possible better opportunity of earning and living have ended up in expansive of urban population, sub-urbanization and urban decay characterized by rapid growth of slums. Dreams of many have confronted the vicissitudes of dismal quality of slum life characterized by insecurity, poor housing and overcrowding. Lack of basic amenities like safe drinking water and proper sewerage system make this population vulnerable to infections. A combined effect of all these factors takes a heavy toll on health and nutrition of the slum dwellers especially on the children. Undernutrition appears to be a plaguing factor for a large proportion of children in India living in slum areas owing to its negative impact on physical and cognitive development.

The city of Kolkata located in eastern part of India has demonstrated a conspicuous rise in its slum growth 
profile in the past few decades. Hitherto, studies on physical growth and nutritional status particularly on preadolescent slum dwellers are lacking. Therefore growth and nutritional studies among slum children becomes impediment to carry to understand the malnutrition in relation to socio economic status. Majority of the studies conducted have focused on the nutritional status of preschool children below 5 years of age and there was only one longitudinal study conducted among the squatter children of Calcutta Municipal Corporation [5]. In some other studies, 51\% of children below 5 years from Kolkata slum [6] were reported to be malnourished. Nutrition Foundation of India [7] studied the growth velocity of the infants living in slum area of Calcutta. Madras and Mumbai and found that the average growth performance of infants of Calcutta was the worst.

India consists of diverse agro-climate regions and ethnic multiplicities. Socio-cultural practices, life-styles and eating habits vary not only between states but also between the districts within a state. The country has adopted a multi-pronged strategy to combat these problems and to improve the nutritional status of the population [8]. One half of the children under the age of five years in India are moderately or severely malnourished, $30 \%$ of new born children are significantly under weight and nearly $60 \%$ of women are anaemic.

The common perception that child under-nutrition is caused solely by poverty and food insecurity, may not be entirely responsible for the under-nutrition milieu in India. Multiple and interrelated factors are normally involved in contributing to high rates of malnutrition. Previous research has shown that certain social factors are important determinants of under-nutrition. India presents a unique combination of such social factors, hence requires a series of tailored strategies and policies to address the current needs [9]. It is wellestablished that socio-economic factors such as lower levels of household wealth and material education are important causes of childhood under nutrition [10].

\section{OBJECTIVES}

In the context of scanty nutritional data on urban slum children, we aimed

1. to investigate the nutritional status (stunting, wasting, and underweight) among 2- 8 year old children as they are the most vulnerable section of population who will be the main force of future India.
2. to observe the association of socio-economic factors with undernutrition of the studied children.

\section{MATERIALS AND METHODS}

\section{Study Area}

This cross sectional study was conducted in a squatter settlement located at Tangra, Behala and Dum Dum areas of the city of Kolkata. The stretch selected for the study is under the jurisdiction of Calcutta Municipal Corporation wards nos.- 4, 58, 123. The majority of inhabitants were Bengali Hindu community. The study was conducted during the period from May 2014 to July 2014.

\section{The Study Population}

This study included 185 children ( 86 boys and 99 girls) of age group 2-8 years. The following table depicts the distribution of participants on the basis of age and sex.

Table 1: Classification of Studied Slum Children Based on Age and Sex

\begin{tabular}{|c|c|c|c|}
\hline \multirow{2}{*}{ Age (yrs) } & \multicolumn{2}{|c|}{ Sex } & \multirow{2}{*}{ Total } \\
\cline { 2 - 3 } & Boys & Girls & \\
\hline \hline 2 & 2 & 9 & 11 \\
\hline 3 & 16 & 14 & 30 \\
\hline 4 & 14 & 15 & 29 \\
\hline 5 & 13 & 15 & 28 \\
\hline 6 & 16 & 17 & 33 \\
\hline 7 & 15 & 16 & 31 \\
\hline 8 & 10 & 13 & 23 \\
\hline Total & $86(46.2 \%)$ & $99(53.5 \%)$ & $185(100 \%)$ \\
\hline
\end{tabular}

Percentages are given in parenthesis.

\section{Anthropometric Variables}

The anthropometric measurements were made following standard techniques [11]. Anthropometry offers a reliable method to access the nutritional status of children. Anthropometry is the single most universally applicable in expensive and noninvasive method available to assess the size, proportion and composition of human body. The following anthropometric measurements were made height $(\mathrm{HT})$, weight $(\mathrm{WT})$. Weight $(\mathrm{kg})$, height $(\mathrm{cm})$ of each subject were taken with the help of Martin's Anthropometer and standard weighing machine. 


\section{Socio-Economic Variables}

Socio-economic information were collected using a semi- structured questionnaire /schedule and personal interview with the parents during household survey. The questionnaire items were selected based on literature search and have been widely used in various studies. The questions include parental education and occupation, total number of family members and average monthly income of the family, age, sex, ethnicity of the subject, their birth order, house type etc. Efforts were made to determine the age of a child accurately, in some case, along with polio card, birth certificates were checked, for reducing the chance of error in calculating the age of an individual.

\section{Assessment of Nutritional Status}

Three commonly used undernutrition indicators, i.e., stunting, underweight and wasting were used to evaluate the nutritional status of the subjects. Internationally accepted the National Centre for Health Statistics (NCHS) age and sex specific - $2 \mathrm{Z}$ scores were used as cut off values to define stunting, (low height for age), underweight (low weight for age) and wasting (low weight for height) [12]. Z-scores were calculated following the standard formula:-

$\mathrm{Z}$ - score $=\frac{\mathrm{X}-\text { Median of NCHS }}{\text { Standard deviation of } \mathrm{NCHS}}$

Where, $\mathrm{X}$ is an individual value

Three Z-scores were calculated

HAZ = Height-for-age Z-score, WAZ = Weight-for-age Z-score

WHZ = Weight-for height Z-score
The following scheme was utilized to define undernutrition:

Stunting: $H A Z<-2$; Underweight: WAZ < - 2; Wasting: $\mathrm{WHZ}<-2$

\section{Statistical Analyses}

Statistical analyses were done by using SPSS (version 11.0). Pearson correlation ( $r$ ) coefficient test was undertaken to measures the undernutrition with various socio - economic variables among the studied population.

\section{RESULTS}

Table 2 shows the prevalence of stunting among boys of age group $3,4,5,6,7,8$ years are $37.5 \%$, $21.42 \%, 38.46 \%, 25 \%, 26.66 \%, 50 \%$ respectively. No stunting boys have been found in the age groups of 2 years. The prevalence of stunting among girls of age group 2,3,4 5,6,7,8 years are $33.3 \%, 57.14 \%, 53.3 \%$, $40 \%, 47.05 \%, 50 \%, 3076 \%$ respectively. The overall prevalence of stunting among the girls are higher than the boys. The overall prevalence for age group $2,3,4,5,6,7,8$ years are $27.27 \%, 46.66 \%, 37.93 \%$, $39.28 \%, 36.36 \%, 38.70 \%, 39.13 \%$ respectively. The total prevalence is $38.91 \%$ (boys $32.14 \%$ and girls $45.45 \%)$.

Table 3 shows the prevalence of underweight among boys of age group 3,4,5,6,7,8, years age are $62.5 \%, \quad 42.85 \%, \quad 53.84 \%, \quad 62.5 \%, \quad 46.6 \%, \quad 40 \%$ respectively. No underweight boys have been found in the age group of 2 years. The prevalence of underweight among girls of age group 2,3,4,5,6,7,8 years are $33.33 \%, 71.42 \%, 40 \%, 53.33 \%, 41.17 \%$, $68.75 \%, 30.76 \%$ respectively. The overall prevalence for age group 2,3,4,5,6,7,8 years are $27.27 \%, 66.66 \%$,

Table 2: Prevalence of Stunting (HAZ) among the Studied Children

\begin{tabular}{|c|c|c|c|}
\hline \multirow{2}{*}{ Age (yrs) } & \multicolumn{2}{|c|}{ Sex } & \multirow{2}{*}{ Total } \\
\cline { 2 - 4 } & Boys & $3(33.33 \%)$ & $3(27.27 \%)$ \\
\hline \hline $2(\mathrm{~N}=11)$ & - & $8(57.14 \%)$ & $14(46.66 \%)$ \\
\hline $3(\mathrm{~N}=30)$ & $6(37.5 \%)$ & $8(53.33 \%)$ & $11(37.93 \%)$ \\
\hline $4(\mathrm{~N}=29)$ & $3(21.42 \%)$ & $6(40 \%)$ & $11(39.28 \%)$ \\
\hline $5(\mathrm{~N}=28)$ & $5(38.46 \%)$ & $8(47.05 \%)$ & $12(36.36 \%)$ \\
\hline $6(\mathrm{~N}=33)$ & $4(25 \%)$ & $8(50 \%)$ & $12(38.70 \%)$ \\
\hline $7(\mathrm{~N}=31)$ & $4(26.66 \%)$ & $4(30.76 \%)$ & $9(39.13 \%)$ \\
\hline $8(\mathrm{~N}=23)$ & $5(50 \%)$ & $45(45.45 \%)$ & $72(38.91 \%)$ \\
\hline Total & $27(32.14 \%)$ & \\
\hline
\end{tabular}


Table 3: Prevalence of Underweight (WAZ) among the Studied Children

\begin{tabular}{|c|c|c|c|}
\hline \multirow{2}{*}{ Age (yrs) } & \multicolumn{2}{|c|}{ Sex } & \multirow{2}{*}{ Total } \\
\cline { 2 - 4 } & Boys & $3(33.33 \%)$ & $3(27.27 \%)$ \\
\hline \hline $2(\mathrm{~N}=11)$ & - & $10(71.42 \%)$ & $20(66.66 \%)$ \\
\hline $3(\mathrm{~N}=30)$ & $10(62.5 \%)$ & $6(40 \%)$ & $12(41.37 \%)$ \\
\hline $4(\mathrm{~N}=29)$ & $6(42.85 \%)$ & $8(53.33 \%)$ & $15(53.57 \%)$ \\
\hline $5(\mathrm{~N}=28)$ & $7(53.84 \%)$ & $7(41.17 \%)$ & $17(51.5 \%)$ \\
\hline $6(\mathrm{~N}=33)$ & $10(62.5 \%)$ & $11(68.75 \%)$ & $18(58.06 \%)$ \\
\hline $7(\mathrm{~N}=31)$ & $7(46.6 \%)$ & $4(30.76 \%)$ & $8(34.78 \%)$ \\
\hline $8(\mathrm{~N}=23)$ & $4(40 \%)$ & $49(49.49 \%)$ & $93(50.27 \%)$ \\
\hline Total & $44(51.16 \%)$ & \\
\hline
\end{tabular}

$41.37 \%, 53.57 \%, 58.06 \%, 34.78 \%$ respectively. The total prevalence is $50.22 \%$ (boys $57.16 \%$, and girls $49.49 \%)$.

Table 4 shows the prevalence of wasting among boys of age group $3,4,5,6,7,8$ years of age are $25 \%$, $21.42 \%, 38.46 \%, 31.25 \%, 20 \%, 60 \%$ respectively. No wasting boys have been found in the age group of 2 years. The prevalence of wasting among girls of age group 2,3,4,5,6,7,8 years are $22.22 \%, 42.85 \%, 20 \%$, $53.33 \%, 29.4 \%, 43.75 \%, 7.69 \%$ respectively. The overall prevalence for age group 2,3,4,5,6,7,8 years are $18.18 \%, 33.33 \%, 20.68 \%, 46.24 \%, 30.30 \%$, $32.25 \%, 30.43 \%$ respectively. The total prevalence is $31.33 \%$, (boys $30.23 \%$, and girls $32.32 \%$ ).

Table 5 showed the correlation of under nutrition with various socio - economic variables. The correlation

Table 4: Prevalence of Wasting (WHZ) among the Studied Children

\begin{tabular}{|c|c|c|c|}
\hline \multirow{2}{*}{ Age (yrs) } & \multicolumn{2}{|c|}{ Sex } & \multirow{2}{*}{ Total } \\
\cline { 2 - 4 } & Boys & $2(22.22 \%)$ & $2(18.18 \%)$ \\
\hline \hline $2(\mathrm{~N}=11)$ & - & $6(42.85 \%)$ & $10(33.33 \%)$ \\
\hline $3(\mathrm{~N}=30)$ & $4(25 \%)$ & $3(20 \%)$ & $6(20.68 \%)$ \\
\hline $4(\mathrm{~N}=29)$ & $3(21.42 \%)$ & $8(53.35 \%)$ & $13(46.24 \%)$ \\
\hline $5(\mathrm{~N}=28)$ & $5(38.46 \%)$ & $5(29.41 \%)$ & $10(30.30 \%)$ \\
\hline $6(\mathrm{~N}=33)$ & $5(31.25 \%)$ & $7(43.75 \%)$ & $10(32.25 \%)$ \\
\hline $7(\mathrm{~N}=31)$ & $3(20 \%)$ & $1(7.69 \%)$ & $7(30.43 \%)$ \\
\hline $8(\mathrm{~N}=23)$ & $6(60 \%)$ & $32(32.32 \%)$ & $58(31.35 \%)$ \\
\hline Total & $26(30.23 \%)$ & & \\
\hline
\end{tabular}

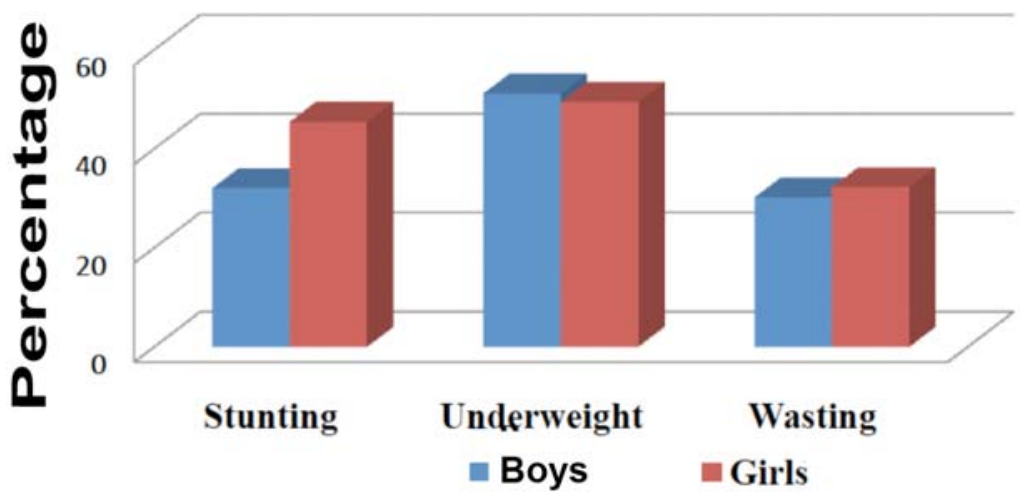

Figure 1: Sex wise distribution of undernutrition. 
Table 5: Correlation ( $r$ ) of Three Conventional Measures of Undernutrition with Various Socio- Economic Variables among the Studied Slum Children

\begin{tabular}{|c|c|c|c|}
\hline Socio-economic variables & HAZ & WAZ & WHZ \\
\hline \hline Household size & $-0.189^{*}$ & $0.180^{*}$ & n.s. \\
\hline Father's education & $0.162^{*}$ & n.s. & n.s. \\
\hline Father's occupation & n.s. & $0.251^{* *}$ & $0.144^{*}$ \\
\hline Mother's education & $0.232^{* *}$ & n.s. & n.s. \\
\hline Mother's occupation & n.s. & n.s. & n.s. \\
\hline Family income & n.s. & n.s. \\
\hline House type & n.s. & n.s. \\
\hline
\end{tabular}

${ }^{*} p<0.05 ;{ }^{* \star}=p<0.01 ;$ n.s. $=$ not significant.

$(r)$ is present in between the household size, fathers' education with stunting and underweight and both are significant at 0.05 probability level. There is a correlation between the mothers' education with stunting, wasting, and underweight and it is highly significant at 0.01 probability level.

\section{DISCUSSION}

Any major deviation in the nutrient intake either in quality or in quantity from its requirement can also affect growth and life span in a number of ways, particularly in the later period of growth. The results of the present study clearly indicated that, based on WHO classification of severity of malnutrition, the overall prevalence of stunting was medium $(20-29)$, whereas those of underweight was very high ( $\geq 30 \%$ ) and wasting ( $\geq 15 \%)$ was high, in both sexes. The rates of underweight were slightly higher than that reported from India (43\%) by UNICEF, [1]. Results on stunting indicated that, there existed medium level of chronic undernutrition due to prolonged food deprivation. The rate of stunting was much less than reported $(48 \%)$ by UNICEF, [1] from India. In case of wasting; it was also observed that there existed a higher rate of undernutrition that was indicative of more recent food deprivation. The rate was slightly higher than those reported (20\%) by UNICEF, [1]. The report of UNICEF, [1] shows that the prevalence of stunting in neighboring countries like Bangladesh, China, Bhutan, Pakistan, Nepal and Sri Lanka are 43\%, 11\%, 40\%, 37\%, 49\% and $14 \%$ respectively; that of underweight in those countries are $48 \%, 7 \%, 19 \%, 38 \%, 39 \%$ and $29 \%$ respectively. Prevalence of wasting in Bangladesh, Bhutan, Pakistan, Nepal and Sri Lanka are 13\%, 3\%, $13 \%, 13 \%$ and $14 \%$ respectively. Among other countries, in Eastern and South Africa, the prevalence of stunting, underweight and wasting is $41 \%, 7 \%$ and
$28 \%$ respectively and in West and Central Africa the prevalence of stunting, underweight and wasting is $48 \%, 43 \%$ and $20 \%$ respectively. The reports of such other studies suggest that the highest rates of stunting is in Nepal (49\%), and that of underweight and wasting are in West Bengal (63.3\% and 50\% respectively) [1, 13]. The lowest rates of stunting and underweight are in USA ( $1 \%$ and $2 \%$ respectively) and that of wasting is in USA and China [1].

Rao and others [14] worked on the change in nutritional status and morbidity overtime among preschool children from slums in Pune, India. Some early studies in this context hard reported a very high prevalence of malnutrition of $94 \%$ among Jabalpur slum children [7] and $82 \%$ among preschool children from Delhi slum area [15]. Awasthi et al. [16] reported a high prevalence of malnutrition, $68 \%$ under-weight, $63 \%$ stunting and $26 \%$ wasting among children below 4 years of age from slums of Lucknow. Two other studies reported more than $60 \%$ prevalence of malnutrition of among under-five children and infants from Vadodara city [17]. A large scale study conducted on 15 Indian cities documented that $92 \%$ of slum dwellers had chronic malnutrition and lower energy intake [18]. Karkarni and Nadakarni [19] found that the growth potential of slum children was low and that was due to environmental, cultural, economic and nutritional factors acting in combination. Mital and Singh [20] studied 482 slum children of Tripuri town, Patiala found that 185 had low weight for age, 222 had low height for age. Malnutrition is more common in females than in males. Bisharat and Zagha [21] studied slum children of Jordan and found that $28 \%$ and $46 \%$ of 3 -year-old male and female children respectively were below $90 \%$ of their reference weight for age. Giugliani and others [22] studied the children over one year in a squatter settlement in Brazil and found that the social determinants were stronger antecedents of malnutrition 
than the biological determinants. It was also observed that a major percentage of these children lack maternal care as their mothers were working. It has been reported that in lower socio-economic group competition for food is likely to be greater in households with more children [23]. Therefore it may be possible that in a larger family with poor socio economic status where the food competition is likely to be higher, lack of parental care coupled lower maternal education, might have made the youngest children more vulnerable to mal nutrition

\section{CONCLUSION}

We conclude from this study that children living in the urban slum of Kolkata are fighting to survive in an expensive urban environment and have been facing a great risk (hamper normal growth and development of the child, can decrease the life span, increases the chance of having viral, bacterial and parasitic diseases) in terms of nutritional stress. Our study also revealed that factors like household size, parents' education were closely related with the nutritional status of a child. As there is no ICDS programme in this area, we propose to the State to undertake preventive and rehabilitative intervention programs like regular supply of mid day meal as an immediate step to ameliorate this problem.

\section{ACKNOWLEDGEMENTS}

We would like to take this opportunity to express our gratitude to all of those who have helped in various ways in completing the work. We are grateful to the study participants and their family members for their cooperation.

\section{REFERENCES}

[1] UNICEF. The State of the world's children, United Nations Children Fund, UNICEF, New York 2007.

[2] Elankumaran C. Malnutrition in Preschool children of Jaffana society - A Post-Exodus statistical perspective. Paper presented in 9th International conference on Srilankan studies, University of Ruhuna, Srilanka, 28-30 November 2003.

[3] Gopalan C, Ramsastri BV, Balasubramanian SC. Recommended Dietary Allowances for Indians. Hyderabad: ICMR 1989.

[4] Gupta VM, Shukla KK. Epidemological correlates of protein energy malnutrition in preschool children. Indian $\mathrm{J}$ Prev Social Med 1992; 23: 26-32.

[5] Ray S. Growth Pattern of Children of Two Social Groups: A One-Year Longitudinal Study. Journal of Huma Ecolog 2004; 15(1): 31-9.
Sen PK. Nutritional status of under five children in an urban slum community of Calcutta. Indian J Public Health 1994; 38: 113-4.

[7] Nutrition Foundation of India. Profiles of Undernutrition and Underdevelopment: Studies of Poor Communities in Seven Regions of the Country. NFI Scientific Report No. 8, New Delhi: Media Workshop NFI 1988.

[8] Economic Survey, Govt. of India 2002-2003, 229-233.

[9] India CLEN and INCLEN Trust. Determinants of under nutrition in children and assessment of management at different levels of health care. New Delhi report, 2010; available at: planningcommission.nic.in/reports/genrep/ multi_nutrition.pdf (accessed on June 10, 2013).

[10] UNICEF. State of World's Children. UNICEF, New York 1998; 7-87.

[11] Lohman TG, Roche AF, Martorell R. Anthropometric standardization Reference Manual. Chicago: Human Kinetics Books 1988; pp. 3-80.

[12] Hamill PV, Drizd TA, Johnson CL, Reed RB, Roche AF, Moore WM. Physical growth: National Center for Health Statistics Percentiles. Am J Clin Nutr 1979; 32: 607-29.

[13] Mandal GC, Bose K, Bisai S, Ganguly S. Under nutrition among the Integrated Child Development Services (ICDS) scheme children aged 2-6 years of Arambagh, Hoogly District, West Bengal, India: a serious health problem. Italian Journal of Public Health 2008; 5(1): 28-33.

[14] Rao S, Joshi SB, Kelker RS.Changes in nutritional status and morbidity over time among pre-school children from slums in Pune, India. Indian Pediatrics 2000; 37(10): 1060-71

[15] Kapil U, Bali P. Nutritional status of pre-school children of urban slum communities in Delhi. Indian Pediatr 1989; 26: 338-342.

[16] Awasthi S, Pande VK. Prevalence of malnutrition and intestinal parasites in preschool slum Children in Lucknow. Indian Pediatr 1997; 34: 599-605

[17] Bhalani KD, Kotecha PV. Nutritional status and gender difference in the children of less than 5 years of age attending ICDS anganwadis in Vadodara city. Indian Journal of Community Medicine 2002; 27: 124-9.

[18] National Nutrition Monitoring Bureau. Report on Urban Population. Hyderabad: National Institute of Nutrition 1994.

[19] Kakarni VA, Nadkarni MG. Anthropometric profile of infants and children of slum dwellers. India Journal of Public Health 1986; 30: 173-7.

[20] Mittal A, Singh J, Ahluwalia SK. Effect of materal factors o nutritional status of 1-5 yrs old children in urban slum population. Idian Journal of Community Medicine 2007; 32(4): 264-7. http://dx.doi.org/10.4103/0970-0218.37691

[21] Bisharat L, Zagha $H$. Health and Population in Squatter Areas in Amman: A Reassessment After 4 Years of Upgrading. Draft Document, Urban Development Department, Amman, Hashemite Kingdom of Jordon 1986.

[22] Giugliani ERJ, Seffrin CF, Golden M. The malnourished children in urban squatter families: A study in porto Alegre, Brazil. Journal of Tropical Paediatries 1987; 33: 194-8. http://dx.doi.org/10.1093/tropej/33.4.194

[23] Hong R. Effect of economic inequality on chronic childhood undernutrition in Ghana. Public Health Nutrition 2007; 10(4): 371-8. http://dx.doi.org/10.1017/S1368980007226035 